\title{
Left Ventricular Basal Inferoseptal Segment
}

National Cancer Institute

\section{Source}

National Cancer Institute. Left Ventricular Basal Inferoseptal Segment. NCI Thesaurus.

Code $C 127660$.

The inferoseptal portion of the basal division of the left ventricular myocardium as

determined using the AHA 17-Segment Model (Cerqueira et al., 2002). 